\title{
Comparison of Oxford Agar, PALCAM and Listeria monocytogenes Blood Agar for the recovery of L. monocytogenes from foods and environmental samples
}

\author{
Marlene Pinto ${ }^{a}$, Solange Burri ${ }^{a}$, Cristina Mena ${ }^{a}$, Gonçalo Almeida ${ }^{a}$, \\ Luísa Carneiro ${ }^{\text {a }}$, Paula Teixeira ${ }^{\text {a,*, Paul A. Gibbs }}{ }^{\text {a,b }}$ \\ ${ }^{\text {a }}$ Escola Superior de Biotecnologia, R. Dr. António Bernardino of Almeida, 4200-072 Porto, Portugal \\ ${ }^{\mathrm{b}}$ Leatherhead Food Research Association, Surrey, UK
}

Keywords: Listeria monocytogenes; Standard selective-plating media; Listeria monocytogenes Blood Agar (LMBA)

\begin{abstract}
This work had as the main objective a comparison between Listeria monocytogenes Blood Agar (LMBA) and the conventional selective agar media, Oxford and PALCAM, relative to its efficacy in the detection of L. monocytogenes in naturally contaminated food and environmental samples. 173 environmental samples and 272 samples of foods were analysed. A higher sensitivity for detection of L. monocytogenes was verified for LMBA than for PALCAM and Oxford. In LMBA L. monocytogenes could be distinguished from other Listeria spp. by detection of hemolysis. In Oxford and PALCAM this distinction was not possible. The higher growth rate of L. innocua cf. L. monocytogenes in selective liquid media could result in a high number of false negatives (nondetection of the target organism on plates, although its presence was observed by other tests, eg. mini-VIDAS LMO). The need for specific media for the detection of L. monocytogenes in food was confirmed. LMBA could be an alternative medium to use together with PALCAM or Oxford. (C) 2001 Elsevier Science Ltd. All rights reserved.
\end{abstract}

\section{Introduction}

Listeria monocytogenes has been regarded as a significant foodborne pathogen only in recent years, although it was recognised as an animal pathogen more than 60 years ago (Murray, Webb, \& Swann, 1926). Since then it has been implicated in various food-associated outbreaks, the outbreak in California during 1985 involving 142 cases with 48 deaths, was probably the final alert to the role of food in disseminating listeriosis (ICMSF, 1996).

Two selective agar media, Oxford and PALCAM, recommended by the International Organisation for Standardisation (ISO) (Anonymous, 1996a), have been widely adopted in the protocols for detection/enumeration of $L$. monocytogenes. The use of these traditional media, however, does not allow differentiation between

\footnotetext{
${ }^{*}$ Corresponding author. Tel.: +351-22-5580094; fax: +351-225580088.

E-mail address: paula@esb.ucp.pt (P. Teixeira).
}

colonies of L. monocytogenes and those of other species of Listeria. Consequently, the detection of L. monocytogenes in foods requires additional identification tests which are laborious, time consuming and costly. Based on the hemolytic capacity of L. monocytogenes, several media have been developed with the objective of its differentiation from the other Listeria species (Cox, Siebeng, Pedrazzini, \& Moreton, 1991; Johansson \& Kankare, 1996; Beumer, Giffel, \& Cox, 1997).

This work had as the main objective a comparison between the L. monocytogenes Blood Agar (LMBA; Johansson \& Kankare, 1996) and the conventional media, Oxford and PALCAM, relative to its efficacy in the detection of $L$. monocytogenes in naturally contaminated food and environmental samples. Although a similar study has already been carried out by Johansson (1998), there is still a need for data related to comparative trials on different isolation media since alterations to the media used in the standard are being considered by the members of ISO Sub Committee 9 (Anonymous, 2000). 


\section{Materials and methods}

173 environmental samples (surface swabs of environments and equipment of dairies) and 272 samples of different commercial food products were collected from Portuguese producers and retailers during the period October 1999-June 2000. Samples were transported to the laboratory inside cold portable insulated boxes. Environmental samples, fresh meats and fresh fish were analysed on the same day as they were collected. The other samples were refrigerated and analysed 1-5 days after collection, always before the best before date. All the samples were analysed using the mini-VIDAS LMO (hereafter referred as mini-VIDAS) method. This is an enzyme-linked fluorescent immunoassay performed in the automated mini-VIDAS instrument, (Anonymous, 1996b) using antibody specific for L. monocytogenes. 25 $\mathrm{g}$ of food samples were placed in $225 \mathrm{ml}$ Fraser broth (or $225 \mathrm{ml}$ half-Fraser broth for dairy products), homogenised in the Stomacher for $2 \mathrm{~min}$, and incubated at $30^{\circ} \mathrm{C}$ for $24 \mathrm{~h}$. One $\mathrm{ml}$ aliquots of these primary enrichments were transferred to $10 \mathrm{ml}$ of secondary enrichment Fraser broth and incubated at $30^{\circ} \mathrm{C}$ for $24 \mathrm{~h}$. The environmental swabs were transferred to $10 \mathrm{ml}$ of half-Fraser broth and incubated at $30^{\circ} \mathrm{C}$ for $48 \mathrm{~h}$. The sample wells of mini-VIDAS reagent strips were inoculated with $0.5 \mathrm{ml}$ of each secondary enrichment broth for food samples, and $0.5 \mathrm{ml}$ of the primary enrichment broth for environmental samples. The results were automatically obtained after $70 \mathrm{~min}$. Enrichment broths were stored at $2-8^{\circ} \mathrm{C}$ and, when samples were positive in the mini-VIDAS (Test value $\geqslant 0.05$ ), were inoculated on LMBA (Johansson \& Kankare, 1996), Oxford Agar and PALCAM Agar and incubated at $37^{\circ} \mathrm{C}$ for $24-48 \mathrm{~h}$ (Oxford Agar and PALCAM Agar) or 48 h (LMBA). Five typical colonies per plate (when possible) were selected for confirmation by the tests of Gram, catalase, oxidase, fermentation of the sugars mannitol, rhamnose and xylose, CAMP test with Staphylococcus aureus ATCC 25923 and API Listeria (BioMérieux 10300).

Sensitivity (\%): Number of positive results by any of the media used, as a percentage of the number of samples positive in mini-VIDAS.

\section{Results and discussion}

$6.4 \%$ of 173 environmental samples and $6.6 \%$ of 272 foods were positive for L. monocytogenes when the miniVIDAS method was used for detection. The number of positive results obtained with LMBA was, with the exception of environmental samples, similar to those obtained by mini-VIDAS and was always superior or equal to those obtained with PALCAM and Oxford (Table 1). $L$. monocytogenes was not detected by LMBA only in one positive environmental sample whereas PALCAM and Oxford did not detect the organism in seven positive environmental samples, in seven positive vegetable samples, in two positive cheese samples and in one fresh cheese sample. Vaz-Velho, Duarte, and Gibbs (2000) found that the mini-VIDAS method detected 8 of 11 positive samples confirmed by the ISO 11290-1 protocol (Anonymous, 1996a), and gave 11 false positive results (i.e. not confirmed by the ISO protocol) in samples of fresh and cold smoked fish.

The medium LMBA presented for all the samples a higher sensitivity for detection of $L$. monocytogenes than the media recommended by ISO (Anonymous, 1996a) (Table 2). The lower sensitivity observed on the media PALCAM and Oxford has already been reported by Johansson (1998) and Johansson et al. (2000) and is possibly related with the concentration of $\mathrm{LiCl}(15 \mathrm{~g} / \mathrm{l})$ which is higher than the concentration of this compound in LMBA $(10 \mathrm{~g} / \mathrm{l})$, or the absence of acriflavine and other

Table 1

Detection of L. monocytogenes in different food and environmental samples by mini-VIDAS LMO and different selective-plating media

\begin{tabular}{|c|c|c|c|c|c|}
\hline \multirow[t]{2}{*}{ Sample type } & \multirow[t]{2}{*}{ Number of samples } & \multicolumn{4}{|l|}{ Positives } \\
\hline & & Mini-VIDAS & $\mathrm{PAL}^{\mathrm{a}}$ & $O x^{b}$ & $\mathrm{LMBA}^{\mathrm{c}}$ \\
\hline Environmental & 173 & $11(6.4 \%)$ & $4(2.3 \%)$ & $4(2.3 \%)$ & $10(5.8 \%)$ \\
\hline Processed meats & 56 & $2(3.6 \%)$ & $2(3.6 \%)$ & $2(3.6 \%)$ & $2(3.6 \%)$ \\
\hline Vegetables & 108 & $12(11.1 \%)$ & $5(4.6 \%)$ & $5(4.6 \%)$ & $12(11.1 \%)$ \\
\hline Cheese & 49 & $3(6.1 \%)$ & $1(2.0 \%)$ & $1(2.0 \%)$ & $3(6.1 \%)$ \\
\hline Fresh cheese & 15 & $1(6.7 \%)$ & $0(0.0 \%)$ & $0(0.0 \%)$ & $1(6.7 \%)$ \\
\hline Fresh fish & 23 & $0(0.0 \%)$ & $0(0.0 \%)$ & $0(0.0 \%)$ & $0(0.0 \%)$ \\
\hline Fresh meats & 8 & $0(0.0 \%)$ & $0(0.0 \%)$ & $0(0.0 \%)$ & $0(0.0 \%)$ \\
\hline Other & 13 & $0(0.0 \%)$ & $0(0.0 \%)$ & $0(0.0 \%)$ & $0(0.0 \%)$ \\
\hline Total & 445 & $29(6.5 \%)$ & $12(2.7 \%)$ & $12(2.7 \%)$ & $28(6.3 \%)$ \\
\hline
\end{tabular}

\footnotetext{
${ }^{a}$ PALCAM agar.

${ }^{\mathrm{b}}$ Oxford agar.

${ }^{\mathrm{c}}$ L. monocytogenes Blood Agar.
} 
Table 2

Sensitivities (\%) of three different selective-plating media in the detection of $L$. monocytogenes

\begin{tabular}{|c|c|c|c|c|c|}
\hline \multirow[t]{2}{*}{ Sample type } & \multirow[t]{2}{*}{ Number of samples } & \multirow[t]{2}{*}{ Positives mini-VIDAS } & \multicolumn{3}{|c|}{ Sensitivity (\%) } \\
\hline & & & PAL $^{\mathrm{a}}$ & $O x^{b}$ & $\mathrm{LMBA}^{\mathrm{c}}$ \\
\hline Environmental & 173 & 11 & 36.4 & 36.4 & 90.9 \\
\hline Processed meats & 56 & 2 & 100 & 100 & 100 \\
\hline Vegetables & 108 & 12 & 41.7 & 41.7 & 100 \\
\hline Cheese & 49 & 3 & 33.3 & 33.3 & 100 \\
\hline Fresh cheese & 15 & 1 & 0 & 0 & 100 \\
\hline
\end{tabular}

${ }^{\text {a PALCAM agar. }}$

${ }^{\mathrm{b}}$ Oxford agar.

${ }^{\mathrm{c}}$ L. monocytogenes Blood Agar.

selective agents that are present in PALCAM and Oxford but not in LMBA. It is well known that microorganisms in foods are often injured so that they become sensitive to the presence of selective agents present in media normally used in their isolation (Mackey, 1999). Although the protocol used in this study includes enrichment steps in Fraser broth or half-Fraser broth, the presence of lithium chloride, sodium chloride, acriflavin, compounds present in Fraser broth, has already been commented upon as detrimental to the recovery of heatinjured L. monocytogenes and other Listeria spp. (Crawford, Beliveau, Peeler, Donnelly, \& Bunning, 1989; Patel \& Beuchat, 1995). Additionally, the media PALCAM and Oxford do not allow a distinction between colonies of Listeria innocua and L. monocytogenes. Similar results were obtained by Johansson (1998) who demonstrated that the selection of five colonies for confirmation from the standard media (Anonymous, 1996a) may not be sufficient if other Listeria species were present. The higher growth rate of $L$. innocua in selective liquid media (Curiale \& Lewus, 1994; MacDonald \& Sutherland, 1994) compared with L. monocytogenes can result in a high number of false negative results on the PALCAM and Oxford media (Table 1). Studies carried out by Scotter et al. (2001) demonstrated that a significant number of false negative results were obtained when large numbers of L. innocua were present in the foods. In previous work, Yokoyama, Maruyama, and Katsube (1998) concluded that most L. inoccua strains produce a bacteriocin-like substance against $L$. monocytogenes that may inhibit growth of the latter organism during enrichment culture.

Compared with PALCAM and Oxford, LMBA reduces time and materials for confirmation, since at the end of the incubation period it was possible to observe hemolytic zones around the colonies of L. monocytogenes allowing distinction of this species from other nonhemolytic species of Listeria such as L. innocua, often present in foods.

As previously reported by Johansson (1998), these results demonstrate the need for more specific media for the detection of L. monocytogenes in foods and environmental samples and suggests that LMBA might be one alternative to use together with PALCAM or Oxford. It is likely that the more selective/indicator media or methods that are used in the examination of a sample, the more likely it is that the results obtained are representative of the true status of the pathogen in the sample.

\section{References}

Anonymous. (1996a). Microbiology of food and feeding stuffs horizontal method for the detection and enumeration of Listeria monocytogenes - Part 1: Detection method. International Standard, ISO 11290-1.

Anonymous. (1996b). VIDAS Listeria monocytogenes. AFNOR, Bio 12/3-03/96.

Anonymous. (2000). Resolutions taken at the 20th meeting of ISO/TC 34/SC 9, Agricultural and food products - microbiology, Vienna 13/ 16 June.

Beumer, R. R., Giffel, M. C., \& Cox, L. J. (1997). Optimization of haemolysis in enhanced haemolysis agar (EHA)-a selective medium for the isolation of Listeria monocytogenes. Letters in Applied Microbiology, 24, 421-425.

Cox, L. J., Siebeng, A., Pedrazzini, C., \& Moreton, J. (1991). Enhanced haemolysis agar (EHA)-an improved selective and differential medium for isolation of Listeria monocytogenes. Food Microbiology, 8, 37-49.

Crawford, R. J., Beliveau, C. M., Peeler, J. T., Donnelly, C. W., \& Bunning, V. K. (1989). Comparative recovery of uninjured and heat-injured Listeria monocytogenes cells from bovine milk. Applied and Environmental Microbiology, 55, 1490-1494.

Curiale, M., \& Lewus, C. (1994). Detection of Listeria monocytogenes in samples containing Listeria innocua. Journal of Food Protection, 57, 1048-1051.

ICMSF. (1996). Microorganisms in foods 5. Characteristics of microbial pathogens. London: Blackie.

Johansson, T. (1998). Enhanced detection and enumeration of Listeria monocytogenes from foodstuffs and food-processing environments. International Journal of Food Microbiology, 40, 77-85.

Johansson, T., \& Kankare, M. (1996). Comparison of three selectiveplating media for isolation of Listeria monocytogenes from fresh broiler cuts. In Slu, IUFoST Symposium of Food Associated Pathogens, 6-8 May, 1996, Upsala, Sweden. In Proceedings of the symposium of food associated pathogens (pp. 228-229). 
Johansson, T., Ahola-Luttila, H., Pirhonen, T., Taimisto, A.-M., Haario, H., Laine, M., \& Salkinoja-Salonen, M. (2000). Improved detection of Listeria monocytogenes in soft mould-ripened cheese. Journal of Applied Microbiology, 88, 870-876.

MacDonald, F., \& Sutherland, A. (1994). Important differences between generation times of Listeria monocytogenes and Listeria innocua in two Listeria enrichment broths. Journal of Dairy Research, 61, 433-436.

Mackey, B.M. (1999). Injured Bacteria. In: B. Lund, T. Baird-Parker, \& G. Gould, The microbiological safety and quality of food (pp. 315-341). Vol. 1. Gaithersburg: Aspen Publishers.

Murray, E. G. D., Webb, R. A., \& Swann, M. B. R. (1926). A disease of rabbits characterised by a large mononuclear leucocytosis caused by a hitherto undescribed bacillus Bacterium monocytogenes (n.sp.). Journal of Pathology and Bacteriology, 29, 407-439.
Patel, J., \& Beuchat, L. (1995). Evaluation of enrichment broths for their ability to recover heat-injured Listeria monocytogenes. Journal of Applied Bacteriology, 78, 366-372.

Scotter, S. L., Langton, S., Lombard, B., Schulten, S., Nagelkerke, N., In't Veld, P. H., Rollier, P., \& Lahellec, C. (2001). Validation of ISO method 11290 Part 1 - Detection of Listeria monocytogenes in foods. International Journal of Food Microbiology, 64, 295-306.

Vaz-Velho, M., Duarte, G., \& Gibbs, P. (2000). Evaluation of miniVIDAS rapid test for detection of Listeria monocytogenes from production lines of fresh to cold-smoked fish. Journal of Microbiological Methods, 40, 147-151.

Yokoyama, E., Maruyama, S., \& Katsube, Y. (1998). Production of bacteriocin-like-substance by Listeria innocua against Listeria monocytogenes. International Journal of Food Microbiology, 40, 133-137. 